\title{
UTILIZAÇÃO DOS MACROINVERTEBRADOS BENTONICOS NA AVALIÇÃO DA QUALIDADE AMBIENTAL DE 10 AFLUENTES DO RIO DO MONJOLINHO, SÃO CARLOS, SP.
}

\author{
Daniele Cristina Schiavone ${ }^{1}$ \\ Marcus Vinícius Nunes ${ }^{2}$ \\ Odete Rocha \\ José Valdecir de Lucca
}

\section{RESUMO}

A comunidade de macroinvertebrados bentônicos aquáticos é bastante diversificada, sendo constituída por representantes de vários grupos taxonômicos. Muitos de seus componentes são organismos bioindicadores de poluição, podendo apresentar alterações fisiológicas, morfológicas ou comportamentais dos indivíduos até alterações na abundância populacional das espécies, indicando assim alterações no ambiente. No presente estudo teve por objetivo avaliar a composição e abundância dos macroinvertebrados bentônicos em 10 afluentes da porção superior da bacia do Rio Monjolinho, São Carlos, SP. A coleta foi realizada no período chuvoso, com amostrador Surber de $0,9 \mathrm{~m}^{2}$ de área amostral, em tréplicas. No laboratório, os macroinvertebrados foram separados, preservados em álcool $70 \%$ e identificados em grandes grupos utilizando a literatura especializada. Foram também realizadas coleta de água para quantificação da concentração de fósforo total. De forma geral, a pesquisa comprovou

\footnotetext{
1 Departamento de Ecologia e Biologia Evolutivo/Universidade Federal de São Carlos (UFSCAr). danischiavone@yahoo.com.br

${ }^{2}$ Programa de Pós-Graduação em Ecologia e Recursos Naturais (PPG-ERN)/Universidade Federal de São Carlos (UFSCAr)
} 
que a comunidade de macroinvertebrados bentônicos foi uma ferramenta adequada para a avaliação da qualidade ambiental e sugere-se que ela seja empregada para monitorar a integridade e preservação das nascentes do rio Monjolinho, um importante recurso hídrico para o abastecimento público de água na cidade de São Carlos.

Palavras - chave: Rio Monjolinho; Bioindicadores, Macroinvertebrados Bentônicos

\section{INTRODUÇÃO}

A preservação dos recursos hídricos tem atualmente uma grande relevância pois os ecossistemas aquáticos sofrem cada vez mais com o aumento de cargas poluidoras, resultado do crescimento desordenado da população humana e do desenvolvimento tecnológico e Industrial (CESTESB, 1982)

O excesso de cargas poluidoras acarreta uma aceleração do processo de eutrofização, levando à perda das qualidades cênicas ao aumento no custo do tratamento de água e ocasionando o desaparecimento de várias espécies aquáticas (AZEVEDO, 2002)

Os limnólogos relacionam as variações nas características ambientais dos rios com a alteração na estrutura da comunidade de insetos e outros invertebrados. Essas análises são utilizadas para testar hipóteses sobre os possíveis fatores que influenciam a estrutura da comunidade de rios, possibilitando também modelar as respostas da biota ás mudanças naturais e antrópicas no ambiente (SILVEIRA, 2004)

Os macroinvertebrados bentônicos de água doce possuem um tamanho superior a 0,5 mm, sendo geralmente visíveis a olho nu (PÉREZ, 1996). Alimentam-se principalmente de algas e microrganismos, situando-se assim numa posição intermediária na cadeia alimentar, tendo como seus principais predadores os peixes e outros vertebrados (SILVEIRA, 2004).

Os macroinvertebrados bentônicos são de grande importância para a dinâmica de nutrientes, pois transformam a matéria orgânica em energia (CALLISTO \& ESTEVES apud MARQUES et. al, 1999).

As técnicas de biomonitoramento de corpos hídricos por meio dos 
macroinvertebrados bentônicos, vem sendo cada vez mais empregadas e aceitas, como um ferramenta adequada para a avaliação da qualidade de água. Apesar de ter sido utilizada principalmente na América do Norte e Europa desde o século XX, sua utilização tem se expandido gradativamente nas últimas décadas (SILVEIRA, 2004).

Os representantes da família Chironomidae são consideramos os mais abundantes da comunidade bentônica, (PINDER, 1983. CALLISTO et al., 2002). Além dos Chironomidae, os Oligochaeta, também são considerados um grupo importante na comunidade bentônica, pois ambos são tolerantes a fatores ambientais extremos. Algumas espécies de Oligochaeta são considerados bioindicadores ambientais, pela ampla tolerância aos efeitos tóxicos causados por metais e poluentes alóctones. (MARCHESE \& EZCURRA DE DRAGO, 1999; PRYGIEL et. al., 2000).

O principal objetivo do presente trabalho foi avaliar a comunidade dos organismos macroinvertebrados bentônicos visando sua utilização como bioindicadores da qualidade da água do rio Monjolinho, São Carlos, SP.

\section{2. ÁREA DE ESTUDO}

Com o objetivo de aumentar a quantidade de água da região, e juntamente a sua qualidade, minimizando os problemas de saúde pública, que são envolvidos, a prefeitura da Cidade de São Carlos - SP, tem desenvolvido um projeto de recuperação ambiental dos córregos à montante da estação de captação de água do Espraiado, área urbana em degradação. Localizada na Área de Preservação Permanente de São Carlos, onde é coletada a água do rio Monjolinho, a estação de captação abastece em média 40 mil habitantes do Município de São Carlos - SP (LEME \& LEME, 2008).

A maior área da Bacia hidrográfica do Rio Monjolinho está localizada no Município de São Carlos e uma pequena parte no município de lbaté - SP, distando aproximadamente $240 \mathrm{~km}$ da capital. Essa sub-bacia está integrada à bacia hidrográfica do rio Jacaré - Guaçu, da qual faz parte, sendo um dos importantes afluentes da margem direita do Rio Tietê. 
A principal característica desta Bacia hidrográfica é o desenvolvimento urbano na Cidade de São Carlos e, em conseqüência, os impactos provenientes das atividades antrópicas.

\subsection{COLETAS E ANÁLISES DOS MACROINVERTEBRADOS BENTÔNICOS}

As coletas foram feitas no período chuvoso de 2010, em 10 estações localizadas em diferentes afluentes da porção superior da bacia do Rio Monjolinho, São Carlos, SP. (Captação, Córrego Martinha, Belvedere Horta, Belvedere Nascente, Espraiado I, Espraiado II, Jatobá, Ponte de Tábua, São Rafael, Embrapa Rei Frango).

O sedimento foi coletado com um amostrador Surber, de área amostral de 0,9 $\mathrm{m}^{2}$, em três repetições de amostragem a cada ponto de coleta. As amostras foram acondicionadas em sacos plásticos não tóxicos e fixadas com formol $4 \%$. No laboratório, os espécimes foram separados, com pinças, em bandejas com iluminação e os organismos encontrados foram acondicionados em frascos com álcool $70 \%$ até 0 momento da identificação. A identificação taxonômica foi feita com a utilização de microscópios estereoscópico e óptico, com a utilização de literatura especializada.

\subsection{COLETA E ANÁLISE DAS VARIÁVEIS QUÍMICAS DA ÁGUA}

Amostras de água para quantificação da concentração de fósforo total foram coletadas em cada ponto de amostragem e acondicionadas em frascos plásticos e armazenadas em freezer na temperatura de $4^{\circ} \mathrm{C}$, até $\mathrm{o}$ momento das análises. A análise seguiu a metodologia descrita por Valderrama, 1981.

\section{RESULTADOS}

Considerando-se todos os pontos de amostragem, o número total de indivíduos da comunidade de macroinvertebrados bentônicos coletados foi de 4115, distribuídos em 16 grupos distintos: Chironomidae, Ceratopogonidae e Dixidae (Díptera), Coleoptera, Ephemeroptera, Trichoptera, Plecoptera, Hemiptera, Odonata, Oligochaeta, Hirudinea, Nematoda, Turbellaria Lepidoptera, Bivalvia e Gastropoda. 
Os representantes da família Chironomidae e Oligochaeta foram os mais abundantes, contribuindo com 53,43\% e 26,70\% respectivamente. Os organismos da Classe Oligocheata foram os mais representativos no ponto da captação de água, atngindo $59,23 \%$ do total. As concentrações de fósforo total (Tabela 1 ) registradas na água dos córregos foram baixas variando de 14,77 $\mu \mathrm{g} / \mathrm{l}$ a 34,34 $\mu \mathrm{g} / \mathrm{l}$ indicando que esses afluentes encontram-se em estado trófico variando de oligotrófico a mesotrófico.

No córrego do Espraiado I foi registrado a menor concentração de fósforo total $(14,77 \mu \mathrm{g} / \mathrm{l})$ na água e diversidade de 9 táxons, indicando uma boa qualidade nesse ponto.

No ponto captação houve predomínio de Oligochaeta. Esse grupo ocorre em baixa riqueza e elevada densidade preferencialmente em ambientes com elevada concentração de matéria orgânica, o que corrobora o maior grau de trofia deste local onde se registrou a maior concentração de fósforo total na água $(34,34 \mu \mathrm{g} / \mathrm{l})$.

Tabela 1. Concentrações de fósforo total registradas pelos afluentes do rio Monjolinho.

\begin{tabular}{lc}
\hline Pontos Amostrados & Fósforo Total $\boldsymbol{\mu g} / \mathbf{l}$ \\
\hline Captação & 34,34 \\
\hline Ponte de Táboa & 34,34 \\
\hline Jatobá & 16,40 \\
\hline Matinha & 21,94 \\
\hline Espraiado II & 33,04 \\
\hline São Rafael & 17,70 \\
\hline Belvedere Horta & 17,05 \\
\hline Belvedere Nascente & 20,97 \\
\hline Espraiado I & 14,77 \\
\hline Embrapa Rei Frango & 32,06 \\
\hline
\end{tabular}

\section{DISCUSSÃO}

A família Chironomidae inclui os representantes considerados mais abundantes da entomofauna aquática. O grupo é possivelmente o mais amplamente adaptado em relação aos demais insetos aquáticos, apresentando diversas adaptações ecológicas e biológicas que os torna aptos a explorar diferentes hábitats (Pinder, 1983). Vivem em todos tipos de águas doces, freqüentemente atingindo elevadas densidades 
populacionais. Suas larvas constituem importante item na dieta de peixes e também podem ser indicadoras da qualidade ambiental, com algumas espécies possuindo exigências ambientais específicas e outras sendo relativamente tolerantes a condições adversas. No presente estudo a Família Chironomidae e os Oligochaetas foram os mais representativos numericamente. Segundo Callisto et al. (2002), os Chironomidae são considerados os mais abundantes na comunidade bentônica e normalmente dominam os ecossistemas aquáticos devido à capacidade de tolerar diferentes tipos de condições extremas (Cranston, 1995; Di Giovanni et al., 1996). Segundo Olive \& Smith (1975) e Persoone \& De Pauw (1979) são os mais tolerantes à poluição orgânica quando comparados a outras larvas de Diptera. Além disso, ocorrem geralmente em altas densidades, apresentam ciclo de vida curto e biomassa elevada, o que thes confere um importante papel no fluxo energético (Coffman \& Ferrington, 1998).

De acordo com diferentes autores (Howmiller \& Beeton, 1971; Aston, 1973; Nutall \& Purvers, 1974), os altos valores de abundância e densidade registrados para os Oligochaeta podem indicar poluição da água. Nos pontos Ponte de Tábua e Capitação onde foi registrada uma elevada densidade dos representantes desta classe indicando um ambiente impactado, com elevada poluição orgânica, e alterado pelas atividades praticadas na sua área de entorno.

\section{CONCLUSÔES}

- Verificou-se uma baixa riqueza taxonômica e a dominância de Chironomidae e Oligochaeta na porção superior da bacia do rio Monjolinho, indicando a existência de severos impactos antrópicos.

- A elevada abundância e densidade de Oligochaeta e, principalmente, de Chironomidae, nos pontos Ponte de Tábua e Capitação demonstraram que a estrutura da comunidade bentônica nestas localidades reflete as alterações deste ecossistema pelas atividades realizadas na área de entorno; 
- Os resultados corroboraram a adequação da comunidade macroinvertebrados bentônicos para o monitoramento do rio Monjolinho, podendo ser utilizados como bioindicadores.

\section{REFERÊNCIAS BIBLIOGRÀFICAS}

AZAVEDO, M.T.P. (2002). Cianobactérias Formadoras de Florações:

Biodiversidade em Águas de Abastecimento. In: Reunião Brasileira de Ficologia, 9., 2002, Aracruz. Resumos. Aracruz: Sociedade Brasileira de Ficologia, 2002. p.19.

CALLISTO, M. et al. Aplicação de um protocolo de avaliação rápida de diversidade de habitats em atividades de ensino e pesquisa (MG-RJ). Acta Limnológica Brasiliensis, v. 34, p. 91-98, 2002.

CALLISTO, M., Moretti, M. \& Goulart, M. 2002. Macroinvertebrados bentônicos como ferramenta para avaliar a saúde de riachos. Revista Brasileira de Recursos Hídricos, 1: 71-82.

COFFMAN, W.P., \& Ferrington, L. 1998. Chironomidae. In: An Introduction to the Aquatic Insects of North America, 3rd Edition, Merritt, R., and K.W. Cummins, Ed. Kandall-Hunt, Dubuque, lowa, p. 635-754.

CRANSTON, P. S., 1995. Introduction to the Chironomidae. In: P. Armitage, P. S. Cranston \& C. V. Pinder (eds.), The Chironomidae: the biology and ecology of nonbiting midges. Chapman \& Hall, New York, p. 1-7.

DI GIOVANNI, M.V., Goretti, E. \& Tamanti, V. 1996. Macrobenthos in Montedoglio Reservoir, central Italy. Hidrobiologia, 321: 17 - 28.

CETESB, 1982. Qualidade das águas interiores do estado de São Paulo. Secretaria de Obras e do Meio Ambiente. 
LEME, R.S. \& LEME P.S. (2008). Recuperação e Requalificação Ambiental de Área Degradada em Taludes com Nascentes em São Carlos - SP. In: Anais do IV CICESCongresso Ibero-Americano de Controle de Erosão e Sedimentos.

MARCHESE, M.; EZCURRA DE DRAGO, I. Use os benthic macroinvertebrates as organic pollution indicators in lotic environmentes os the Paraná River drainage basin. Polskie Archiwum Hydrobiologii, v.46, n. 3-4, p. 233-255, 1999.

MARQUES, M. G. S. M., FERREIRA, R.L e BARBOSA, F. A. R. A comunidade de macroinvertebrados aquáticos e características limnológicas das Lagoas Carioca e da Barra, Parque Estadual do Rio Doce, MG. Revista Brasileira de Biologia, 59 (2) ,1999, p 203-210.

OLIVE, J.H. \& Smith, K.R. 1975. Benthic macroinvertebrates as indexes of water qualitiy in Scioto River Basin, Ohio, Bult. Ohio Biol. Surv. 5 (2), 124p.

PÉREZ, G. R. Guía para el estudio de los macroinvertebrados acuáticos del Departamento de Antioquia. Universidad de Antioquia, 1996. p. 217.

PINDER, L.C.V. The larvae of Chironomidae (Díptera) of the Holartic region- Introduction. Entomologica Scandinavica Supplement, v. 19, p. 7-10, 1983.

PRYGIEL, J. et al. Use of oligochaeta communities for assessment os ecotoxicological risk in fine sediment os rivers and canals of the Artois - Picardie water basin (France). Hydrobiologia, v. 410, p. 25-35, 2000.

SILVEIRA, M. P. Aplicação do biomonitoramento da qualidade da água em rios. Meio Ambiente. Documentos n. 36, Embrapa, 2004, 68 p. 
SILVEIRA, M. P.; QUEIROZ, J. F. de; BOEIRA, R. C. Protocolo de coleta e preparação de amostras de macroinvertebrados bentônicos em riachos.

Comunicado técnico n. 19, Embrapa, 2004, 7 p.

VALDERRAMA, J.C. (1981). The Simultaneos Analysis of Total Nitrogen and Total Phosphorus in Natural Waters. Mar. Chem., v. 10, p. 109-122. 